\title{
Prevalence, Incidence, and Severity of Sorghum Diseases in Western Kenya
}

\author{
H. K. Ngugi and S. B. King, International Crops Research Institute for Semi-Arid Tropics (ICRISAT), P.O. Box \\ 39063, Nairobi, Kenya; G. O. Abayo, Kenya Agricultural Research Institute (KARI), Kibos National Sugar Re- \\ search Centre, P.O. Box 1221, Kisumu, Kenya; and Y. V. R. Reddy, ICRISAT, Patancheru P.O. Andhra Pradesh, \\ 502324 , India
}

\begin{abstract}
Ngugi, H. K., King, S. B., Abayo, G. O., and Reddy, Y. V. R. 2002. Prevalence, incidence, and severity of sorghum diseases in western Kenya. Plant Dis. 86:65-70.

To assess the prevalence and severity of sorghum diseases in western Kenya, a 2-year survey was conducted (July 1995 and 1996), in 91 and 109 farmers' fields, respectively. Fields were generally $<0.5$ ha and production environment ranged from warm-humid to warm-semi-arid. Fourteen foliar and six panicle diseases were observed, with limited variation in disease prevalence and severity between the 2 years. The most common foliar diseases observed were (in decreasing order of prevalence) oval leaf spot (Ramulispora sorghicola), rust (Puccinia purpurea), ladder leaf spot (Cercospora fusimaculans), zonate leaf spot (Gloeocercospora sorghi), gray leaf spot (Cercospora sorghi), leaf blight (Exserohilum turcicum), and anthracnose (Colletotrichum sublineolum); with prevalence ranging from 95 to $97 \%$ of fields for oval leaf spot, and 44 to $65 \%$ of fields for anthracnose. Head smut (Sporisorium reilianum), was observed in 73 to $75 \%$ of fields, covered kernel smut (S. sorghi) 42 to $43 \%$ of fields, and loose smut $(S$. cruenta) 14 to $24 \%$ of fields. Head smut incidence was $>25 \%$ in $3 \%$ of fields surveyed. Grain yield reduction from smut diseases alone was estimated to be $5 \%$. Out of eight probability distribution functions compared, the double Gaussian model best described the frequency of disease severity levels for most diseases. Based on the best-fitting model, the proportion of fields with disease severity level thought to cause yield loss (severity rating $>5$ on a 1 to 9 scale, where $1=$ no disease) was calculated as $26.6 \%$ for oval leaf spot, $15.3 \%$ for rust, $14.8 \%$ for anthracnose, $4.8 \%$ for ladder leaf spot, and $1.5 \%$ for leaf blight. The production environment influenced the prevalence of disease severity. Severe anthracnose, leaf blight, and ladder leaf spot were confined to fields in the humid LM1 and LM2 agro-ecological zones, rust was ubiquitous, and severe gray leaf spot was more prevalent in the dryer LM4 zone.
\end{abstract}

Additional keywords: beta, binomial, lognormal, negative binomial, Peronosclerospora sorghi, Pólya-Aeppli, Sorghum bicolor, Weibull

Sorghum (Sorghum bicolor (L.) Moench) is ranked second to fifth most important cereal crop in eastern Africa $(8,6)$. However, grain yields currently estimated at $925 \mathrm{~kg} \mathrm{ha}^{-1}$ (6) are low relative to those in other parts of the world in spite of attainable yields $>5,000 \mathrm{~kg} \mathrm{ha}^{-1}$ being commonly reported from experimental plots in this region (ICRISAT, unpublished reports). The causes of low sorghum yields are complex and include losses due to disease and insect pests $(7,8,16,18)$. Most fungal pathogens reported on sorghum worldwide occur in eastern Africa, and often infect susceptible cultivars concomitantly $(3,7,8,12,16)$. However, there is a

Corresponding author: H. K. Ngugi

E-mail: hngugi@yahoo.com

Current address: Department of Plant Pathology,

University of Georgia, Athens 30602.

Currrent address of S. B. King: 1448 Hampton Circle, Goshen, IN 46526.

Accepted for publication 24 September 2001

Publication no. D-2001-1126-01R

(C) 2002 The American Phytopathological Society fields with the highest level of disease rather than a mean incidence for many fields, and provided no data on the prevalence of severely infected fields within the region. Although incidence of downy mildew may exceed $30 \%$ in some fields in eastern Africa, such high levels of the disease are uncommon (3).

The incidence of sorghum diseases may vary considerably with geographical location. For example, a planting of an introduced sorghum cultivar in the lake region of Tanzania developed a high incidence of covered smut (Sporisorium sorghi) in the heavy montmorillonitic clays of the valley, but very little disease developed on a planting of the same cultivar in the coarse sands in the hilltops (3). The influence of agroecological zones on severity of foliar diseases has also been suggested in Ethiopia (9) and western Africa (23), while severe systemic infection of maize by sorghum downy mildew (Peronosclerospora sorghi) in Nigeria was reported to be confined to the southern humid zone (1). Over $70 \%$ of the sorghum in Kenya is produced in the Lake Victoria basin $(17,25)$, an area characterized by diverse climate, physical geography, edaphic factors, and farming practices (10). These factors probably influence the distribution and severity of sorghum diseases, but detailed information on these effects is lacking.

Because most models relating yield to disease incorporate information on disease incidence and severity, obtaining these data is a prerequisite for developing a reliable quantitative assessment of the economic impact of diseases $(11,13,21,22)$. Such information can be obtained on a regional scale through disease surveys $(21,25)$. Surveys can also reveal the effectiveness and desirability of existing or recommended disease management practices as well as factors that farmers may consider in adopting new technologies such as improved cultivars. Initial reports on factors limiting sorghum production concluded that disease constraints were not important enough to warrant studies on individual diseases $(3,7)$. However, in a departure from this view, Hulluka and Esele (8) and Esele (5) identified specific diseases as requiring research in sorghum improvement programs in eastern Africa. An accurate assessment of relative importance of sorghum diseases in Kenya is needed to help target research priorities and justify resource use. The aim of the sorghum dis- 
ease surveys reported here, therefore, was to determine the prevalence, incidence, severity, and distribution of sorghum diseases in western Kenya, the major sorghum production area of Kenya.

\section{MATERIALS AND METHODS}

Survey area. The area covered in the surveys lies between $34^{\circ}$ and $35^{\circ}$ east longitude and $2^{\circ}$ on either side of the Equator (Fig. 1). A circular route covering two provinces (nine districts) was followed in July 1995 and again in July 1996. The surveys were timed to coincide with crop maturity; the sorghum crop was between milk stage and hard dough stage in all fields sampled. The survey transect was approximately $1,000 \mathrm{~km}$ long each year and covered fields in seven different agroecological zones. Kenya is divided into six main agro-ecological zones, each with further subdivisions based on altitude, mean annual rainfall, temperature, and evapotranspiration $(2,10)$. The classification of Jaetzold and Schmidt (10), which is adopted for the purpose of this study, also includes the probability of annual rainfall in a given zone exceeding a certain amount in 6 of 10 years, as well as that of successfully growing the main crops of that zone.

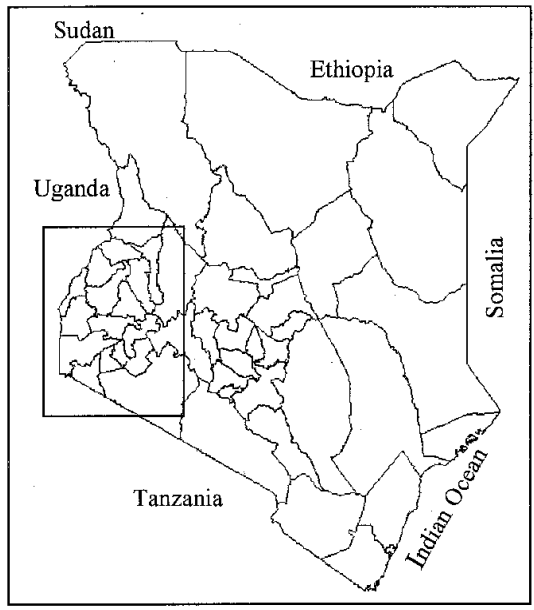

Fig. 1. Map of Kenya showing district borders and the regions covered (box) in surveys carried out in July 1995 and in July 1996 to assess the prevalence, incidence, and severity of sorghum diseases in western Kenya.
A brief description of the zones that were well represented in the two surveys is provided in Table 1.

Sampling and data collection. Ninetyone and 109 fields were assessed along the same route in 1995 and 1996 surveys, respectively. Every effort was made to sample the same fields in 1996 that were sampled in the 1995 survey. However, this was not always possible, and sometimes adjacent fields were sampled. Fields were selected systematically along the route by stopping at 5- to 8-km intervals except when there was no suitable field available, and then the next sorghum field was sampled. Fields were assessed only if the sorghum crop was in milk stage or later maturity stage. At each site, a W-pattern was used to cover the whole field on foot, making five stops to evaluate a total of 50 plants for the foliar diseases, while 100 plants were evaluated for incidence of panicle diseases and systemic downy mildew.

For foliar diseases, severity was assessed on a 1 to 9 scale where $1=$ no disease, $2=$ disease affecting 1 to $4 \%$ area of top 5 leaves, $3=5$ to $9 \%, 4=10$ to $19 \%, 5$ $=20$ to $29 \%, 6=30$ to $44 \%, 7=45$ to $59 \%, 8=60$ to $75 \%$, and $9=>75 \%$ of leaf area affected. The mean rating for 50 plants was calculated for each field. For panicle diseases (smuts and ergot) and systemic downy mildew ( $P$. sorghi) diseases, incidence data were based on a sample of 100 plants per field. Plants infected with head smut ( $S$. reilianum), systemic downy mildew (P. sorghi), and loose smut (S. cruenta) produce no grain. Plants infected with covered smut (S. sorghi) usually produce some grain, so the proportion of panicle area replaced by smut sori was estimated to determine the contribution of this disease to yield losses from smut diseases. Sorghum cultivars were classified either as "local landrace" or "improved", and whenever the farmer was available, effort was made to obtain the cultivar name. Additional information was collected on soil type, cropping system and arrangement pattern, altitude, slope, and crop growth stage.

Data analysis. For each disease, prevalence and incidence or severity data were summarized. The number of fields within each severity category was expressed as a percentage of the total number of fields surveyed to obtain severity frequency distributions. Kolmogorov-Smirnoff twosample tests (GENSTAT 5, Rothamstead Experimental Station, Harpenden, UK), and analysis of deviance (ANODEV) (15) were used to determine whether the proportion of fields within each category of disease severity differed between the 2 years of the survey. In the absence of significant differences between years in the distribution of disease severity levels, data for the 2 years were pooled for further analysis. The beta-type II, gamma, lognormal, negative binomial, normal, Weibull, double-Gaussian, and PólyaAeppli probability distributions were fitted to the data for each disease and assessed for their suitability to describe the data. These distributions have been used to analyze both biotic and abiotic data and cover a wide range of shapes $(11,14)$. Criteria for goodness of fit included residual deviance (15), plots of observed and fitted values, and plots of residual values against fitted values. A distribution was accepted as having a good fit to the data for a particular disease if the residual deviance had a $\chi^{2}$ probability $>0.05$. The proportion of fields with an arbitrary selected severity threshold level (i.e., number of fields with a disease severity score $>5$ at which level disease is thought to significantly affect yield) was computed for each disease based on the three models with the best fit. All statistical computing was done using GENSTAT 5 Release 3.2 (Rothamstead Experimental Station).

In order to assess the relationship between agro-ecological zones and disease severity, curves illustrating the frequency of fields with a given disease severity rating in each zone were constructed for diseases with a prevalence $>50 \%$ of fields sampled. However, owing to the highly skewed distribution of the number of fields within the nine disease severity classes, it was necessary to reduce the number of severity categories. Disease severity categories were thereby reduced to three by combining fields with mean ratings of two and three to represent fields with low disease severity, mean ratings of four

Table 1. A summary description of the agro-ecological zones covered in the 1995 and 1996 sorghum disease surveys based on the classification of Jaetzold and Schmidt (10)

\begin{tabular}{|c|c|c|c|c|c|c|}
\hline Zone & $\begin{array}{l}\text { General } \\
\text { description }\end{array}$ & R/PET ${ }^{a}(\%)$ & Altitude (m) & $\begin{array}{l}\text { Mean } \\
\text { temperature }(C)\end{array}$ & $\begin{array}{l}\text { Mean annual } \\
\text { rainfall }(\mathrm{mm})\end{array}$ & $\begin{array}{l}60 \% \text { rainfall } \\
\text { reliability }{ }^{b}(\mathrm{MM})\end{array}$ \\
\hline LM1 & Warm-humid & $>80$ & $1,300-1,500$ & $20.5-21.7$ & $1,600-1,800$ & $900-1,000(500-700)$ \\
\hline LM2 & Warm-humid & $65-80$ & $1,300-1,500$ & $20.5-21.7$ & $1,300-1,700$ & $700-950(400-650)$ \\
\hline LM3 & Warm-humid & $50-65$ & $1,140-1,450$ & $20.8-22.7$ & $900-1,500$ & $500-900(230-450)$ \\
\hline LM4 & Warm-transitional & $40-50$ & $1,140-1,350$ & $21.4-22.7$ & $800-900$ & $350-500(150-200)$ \\
\hline LM5 & Semi-arid & $25-40$ & $1,135-1,300$ & $21.7-22.7$ & $700-900$ & $250-500(50-100)$ \\
\hline UM1 & Temperate-humid & $>80$ & $1,500-1,700$ & $19.9-20.5$ & $1,600-1,800$ & $800-1,000(500-700)$ \\
\hline $\mathrm{UM} 2 / 3$ & Temperate-sub/semi-humid & $50-80$ & $1,450-1,700$ & $19.3-21.1$ & $1,400-1,600$ & $800-900(450-500)$ \\
\hline
\end{tabular}

a $\mathrm{R} / \mathrm{PET}=$ rainfall as a proportion of potential evapotranspiration; a measure of moisture availability.

b Amount of rainfall exceeded in 6 of 10 years in the long rains and short rains (values in italics) rainfall seasons. 
and five as moderate severity, and mean severity ratings $>6$ as severe disease levels. The proportion of fields in each disease severity category in each of the agro-ecological zones was then computed as a percentage of the total number of fields in which the particular disease was observed. Agro-ecological zones represented by fewer than five fields were not included in this analysis.

\section{RESULTS}

General observations. Subsistence farmers grew all of the sorghum surveyed under low-input cropping systems. Most of the fields surveyed were $<0.5$ ha. Conditions of the fields varied from wellmaintained to very poorly maintained to near-abandoned, with a uniform distribution of these conditions across the fields surveyed in both years. The agronomic

Table 2. Prevalence of sorghum foliar diseases observed in western Kenya during the 1995 and 1996 surveys

\begin{tabular}{lcc}
\hline & & Fields with disease (\%) $^{\mathbf{a}}$ \\
\cline { 2 - 3 } Disease & $\mathbf{1 9 9 5}$ & $\mathbf{1 9 9 6}$ \\
\hline Oval leaf spot (Ramulispora sorghicola) & 95 & 97 \\
Rust (Puccinia purpurea) & 78 & 86 \\
Ladder leaf spot (Cercospora fusimaculans) & 82 & 75 \\
Zonate leaf spot (Gloeocercospora sorghi) & 88 & 52 \\
Grey leaf spot (Cercospora sorghi) & 75 & 58 \\
Leaf blight (Exserohilum turcicum) & 78 & 54 \\
Anthracnose (Colletotrichum sublineolum) & 65 & 44 \\
Sooty stripe (Ramulispora sorghi) & 30 & 20 \\
Rough leaf spot (Aschochyta sorghina) & 17 & 3 \\
Downy mildew (Peronosclerospora sorghi) & 39 & 33 \\
Bacterial streak/stripe (Xanthomonas campes- & & 30 \\
tris/Pseudomonas andropogonis) & 28 & 27 \\
Bacterial leaf spot (Pseudomonas syringae) & 22 & 3 \\
Tar spot (Phyllachora sacchari) & 4 & \\
\hline
\end{tabular}

$\overline{\mathrm{a}} \mathrm{n}=91$ and 109 fields in 1995 and 1996, respectively.

${ }^{\mathrm{b}}$ Causal agent could not be distinguished based on symptoms alone.

condition of the crops also equally varied but in most cases was poor. It was difficult to determine, however, whether this reflected poor crop management or limitations in edaphic factors. Seventy-nine and $77 \%$ of the fields sampled in 1995 and 1996, respectively, were planted to local landraces. Of the farmers interviewed, nearly all identified the parasitic weed Striga hermonthica as a serious problem. Farmers were able to identify smuts as diseases, but did not recognize foliar diseases and in a few cases mistakenly associated severe leaf disease symptoms with natural signs of crop maturity.

Disease prevalence. The most commonly observed foliar fungal diseases in decreasing order of prevalence were oval leaf spot (Ramulispora sorghicola), rust (Puccinia purpurea), ladder leaf spot (Cercospora fusimaculans), zonate leaf spot (Gloeocersospora sorghi), gray leaf spot (Cercospora sorghi), leaf blight (Exserohilum turcicum), and leaf anthracnose (Colletotrichum sublineolum) (Table 2). Three bacterial foliar diseases were also observed, but it was not possible to determine by symptoms alone the difference between bacterial pathogens involved. These were therefore grouped only by symptom type as bacterial leaf streak/stripe (28 to $30 \%$ of

Table 3. Incidence of downy mildew, ergot, and three smut diseases observed in western Kenya during the sorghum disease surveys in July 1995 and July 1996

\begin{tabular}{|c|c|c|c|c|c|c|c|c|c|c|}
\hline \multirow[b]{3}{*}{ Disease } & \multicolumn{10}{|c|}{ Percent of fields with incidence $(\%)^{a}$} \\
\hline & \multicolumn{5}{|c|}{1995} & \multicolumn{5}{|c|}{1996} \\
\hline & $\mathbf{0}$ & $1-2$ & 3-5 & 6-25 & $>25$ & $\mathbf{0}$ & $1-2$ & 3-5 & $6-25$ & $>25$ \\
\hline Downy mildew (Peronosclerospora sorghi) & 61.5 & 26.4 & 4.4 & 4.4 & 3.3 & 66.9 & 22.0 & 5.4 & 3.8 & 1.8 \\
\hline Ergot (Sphacelia sorghi) & 84.5 & 15.5 & 0.0 & 0.0 & 0.0 & 89.0 & 7.3 & 1.8 & 1.8 & 0.0 \\
\hline Head smut (Sporisorium reilianum) & 25.3 & 44.0 & 15.4 & 13.2 & 2.2 & 27.5 & 45.9 & 9.2 & 13.8 & 3.7 \\
\hline Covered kernel smut $(S \text {. sorghi })^{\mathrm{b}}$ & 53.4 & 36.3 & 7.6 & 2.4 & 0.0 & 57.8 & 26.6 & 8.3 & 7.3 & 0.0 \\
\hline Loose smut ( $S$. cruenta) & 83.7 & 12.1 & 4.1 & 1.1 & 0.0 & 76.1 & 15.6 & 6.4 & 1.8 & 0.0 \\
\hline
\end{tabular}

a Out of 91 and 109 fields sampled in 1995 and 1996, respectively; incidence based on a sample of 100 plants in each field.

b Mean panicle damage estimated to be $60 \%$.

Table 4. Chi-square probability values of residual deviance for probability distribution functions fitted to the number of fields within each disease severity category on a 1 to 9 scale, and estimated percentage of fields with disease severity $>5$ (values in bold) based on the three best-fitting distributions for the seven foliar diseases found in over 50\% of the fields surveyed in western Kenya in July of 1995 and 1996

\begin{tabular}{|c|c|c|c|c|c|c|c|c|}
\hline \multirow[b]{2}{*}{ Disease } & \multicolumn{8}{|c|}{ Model $^{\text {ab }}$} \\
\hline & Beta-II & Gamma & Lnormal & Nbinomial & Normal & Weibull & DGE & Poly-app \\
\hline Anthracnose & $\ldots$ & 0.001 & 0.000 & 0.000 & $\begin{array}{l}0.355 \\
14.8\end{array}$ & 0.000 & $\ldots$ & 0.022 \\
\hline Leaf blight & $\begin{array}{l}0.702 \\
1.3\end{array}$ & 0.615 & $\begin{array}{l}0.694 \\
1.5\end{array}$ & 0.109 & 0.040 & 0.443 & $\begin{array}{l}0.938 \\
1.9\end{array}$ & 0.100 \\
\hline Oval leaf spot & $\ldots$ & 0.009 & 0.006 & 0.000 & 0.000 & 0.005 & $\begin{array}{l}0.495 \\
26.6\end{array}$ & 0.000 \\
\hline Gray leaf spot & 0.627 & $\begin{array}{l}0.919 \\
1.2\end{array}$ & 0.432 & 0.996 & 0.927 & $\begin{array}{l}0.986 \\
1.4\end{array}$ & 0.990 & $\begin{array}{l}0.996 \\
0.0\end{array}$ \\
\hline Ladder leaf spot & $\begin{array}{l}0.686 \\
3.2\end{array}$ & 0.375 & $\begin{array}{l}0.698 \\
3.0\end{array}$ & 0.009 & 0.001 & 0.365 & $\begin{array}{l}0.590 \\
4.8\end{array}$ & 0.009 \\
\hline Rust & $\cdots$ & $\begin{array}{l}0.692 \\
13.0\end{array}$ & 0.228 & 0.539 & 0.082 & $\begin{array}{l}0.729 \\
13.0\end{array}$ & $\begin{array}{l}0.981 \\
15.3\end{array}$ & 0.529 \\
\hline Zonate leaf spot & $\ldots$ & $\begin{array}{l}0.980 \\
0.0\end{array}$ & $\begin{array}{l}0.989 \\
0.0\end{array}$ & $\begin{array}{l}0.149 \\
0.0\end{array}$ & 0.409 & 0.836 & $\begin{array}{l}1.000 \\
0.0\end{array}$ & 0.092 \\
\hline
\end{tabular}

${ }^{\mathrm{a}}$ Beta-II $=$ beta probability distribution function, Lnormal $=$ lognormal, Nbinomial $=$ negative binomial, $\mathrm{DGE}=$ double Gaussian with equal variance Poly-app $=$ Pólya-Aeppli. Probability values $>0.05$ indicate a good fit.

${ }^{\mathrm{b}}$ Missing values indicate diseases for which the model could not be fitted to the data. 
fields) and bacterial leaf spot (22 to $27 \%$ of fields). Symptoms of zonate leaf spot were observed on leaf sheaths in over $50 \%$ of fields surveyed (data not shown).

Head smut (S. reilianum) was the most commonly observed of the panicle diseases, being observed in 73 to $75 \%$ of fields, followed by covered kernel smut ( $S$. sorghi) and loose smut (S. cruenta) in 42 to $47 \%$ and 7 to $24 \%$ of fields, respectively (Table 3). Long smut (Tolyposporium ehrenbergii) was not observed in any of the fields in either year. Sorghum downy mildew (P. sorghi) was observed in 33 to $39 \%$ of fields and ergot (Sphacelia sorghi) in 11
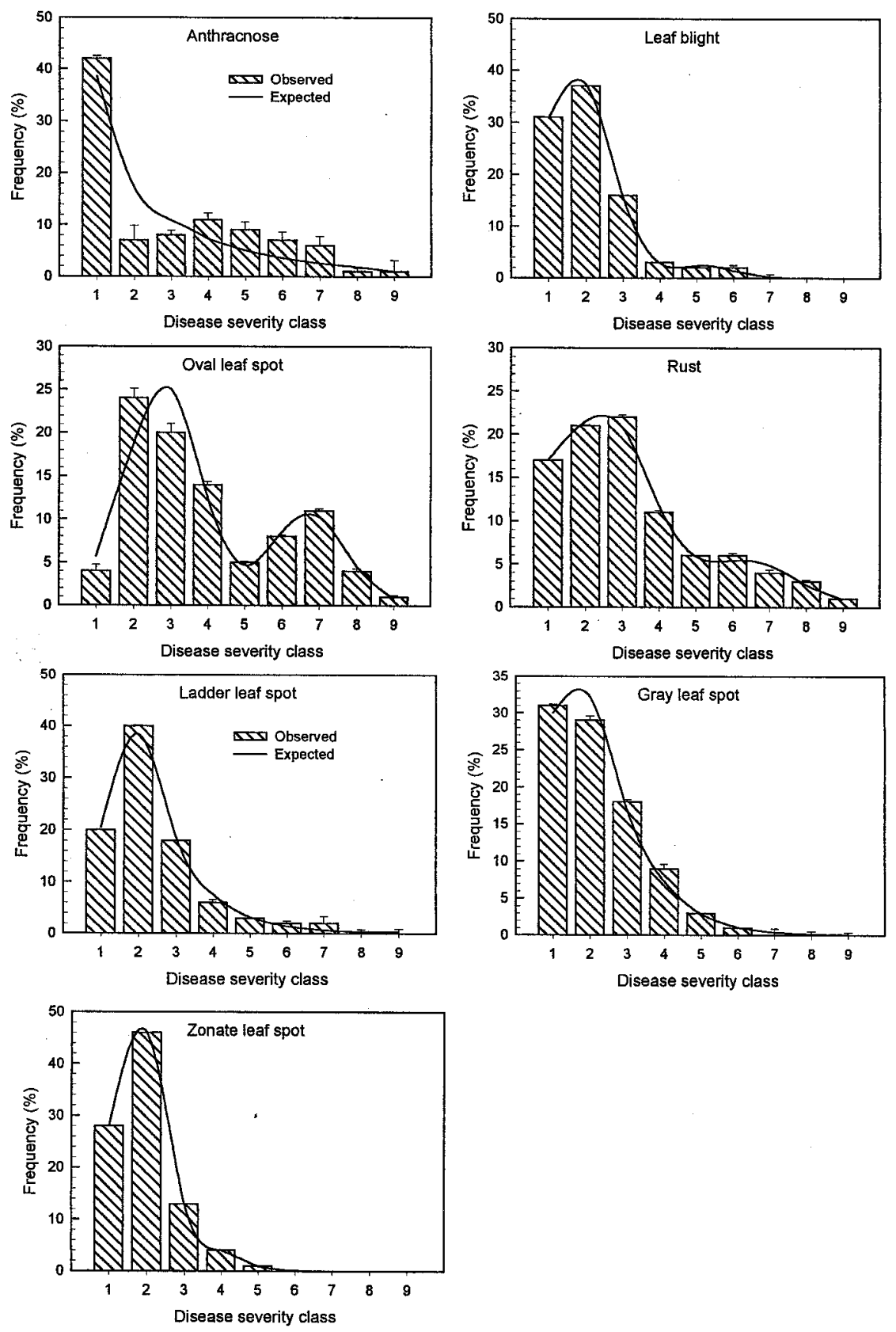

Fig. 2. Frequency distribution for observed (bars) and fitted (line) values based on the best-fit models (Table 4 ) for disease severity levels where $1=$ no disease, $2=$ disease affecting 1 to $4 \%$ area of top 5 leaves, $3=5$ to $9 \%, 4=10$ to $19 \%, 5=20$ to $29 \%, 6=30$ to $44 \%, 7=45$ to $59 \%, 8=60$ to $75 \%$, and $9=>75 \%$ of leaf area affected.
Distribution of disease severity. The frequency of disease severity ratings for each of the seven diseases analyzed was fit by at least one probability distribution function with a residual deviance $\chi^{2}$ probability $>0.05$ (Table 4). In general, the double Gaussian model provided the best fit for most diseases. Attempts to fit the beta type-II distribution to anthracnose, oval leaf spot, rust, and zonate leaf spot data failed. Oval leaf spot was only well fit by the double Gaussian distribution, indicating that most fields either had severe levels of disease (mean severity score $=6$ on a 1 to 9 scale) or low severity (mean severity score $=2$ ). The double-Gaussian distribution model with equal variance also provided a good fit for rust ratings (Fig. 2). Only the normal distribution fit anthracnose data with a $\chi^{2}$ probability for a residual deviance $>0.05$. Even for this distribution, however, plots of fitted against observed values revealed that the percentage of fields with disease severity $>5$ was underestimated (Fig. 2). Overall, gray leaf spot, zonate leaf spot, and rust were fit by most distributions (Table 4). Leaf blight was fit by the beta-II, gamma, lognormal, double-Gaussian, and Weibull but not by the normal probability distribution models. Frequency plots of mean severity ratings for leaf blight, ladder leaf spot, and zonate leaf spot were highly skewed to the left (Fig. 2) indicating disease prevalence was high but severity in most fields was low.

Disease severity across agro-ecological zones. There was a marked difference in disease severity across agro-ecological zones (Fig. 3). For both anthracnose and leaf blight, the total number of fields infected, fields with severe disease, and fields with moderate disease severity were predominant in the higher rainfall/more humid zones (LM1 and LM2) (Fig. 3). Fields with severe anthracnose or leaf blight occurred only in these two zones, while fields with moderate levels of either disease were also observed in LM3 (Fig. $3)$. Severe gray leaf spot was more prevalent in zones LM3 and LM4, while the curve for fields with low oval leaf spot severity was skewed to the left (the more humid LM1 and LM2) indicating that high humidity did not necessarily lead to the development of severe or moderate levels of oval leaf spot (Fig. 3). Rust, oval leaf spot, and ladder leaf spot had cone-shaped curves indicating a ubiquitous distribution of disease severity across zones, with a peak in LM3 (Fig. 3).

\section{DISCUSSION}

This study provides the first quantitative report on the prevalence and severity of sorghum diseases in western Kenya. Previous studies that listed diseases as constraints to sorghum production in this region $(3,7,17,25)$ did not quantify disease prevalence or severity, without which it is difficult to ascribe relative importance to 
any of the diseases. Fourteen foliar and six panicle diseases were observed on sorghum in this survey, with little variation in prevalence between 1995 and 1996. However, few of the foliar diseases were observed at severity levels considered sufficient to significantly affect yield. Oval leaf spot, anthracnose, rust, ladder leaf spot, gray leaf spot, and leaf blight were the only foliar diseases observed at high severity levels under the current production systems. The results of this study confirmed the observations of Guiragossian (7), who listed these diseases as constraints to sorghum production in this region.

Head smut, covered smut, and loose smut, in that order, were also thought to cause significant yield losses and should be considered for further investigation. Long smut ( $T$. ehrenbergii) has been reported as an important disease in Kenya $(7,8)$. However, based on the results of our study, this classification is considered erroneous since this disease was not observed in any of the fields visited in either year of the survey. It is possible that the previous studies refer to other production regions such as eastern Kenya, where this disease has been observed (Bock C. H., personal communication). Nevertheless, the area covered in the present study accounts for $>70 \%$ of all sorghum produced in Kenya $(17,20)$, and as such is more representative of the sorghum production in the country. Efforts should be made to keep this disease excluded from western Kenya.

Disease severity was not uniformly distributed among fields in the region. Although the prevalence of most of the foliar diseases was high, severity in a majority of the fields was too low to impact yields. The exceptions to this included anthracnose, rust, and oval leaf spot. About $15 \%$ of 200 fields surveyed had severe anthracnose (disease severity $>5$ on 1 to 9 scale), while for both rust and oval leaf spot, fields could be classified in two distinct groups; those with low disease severity and those with high severity, the latter comprising $27 \%$ of fields for oval leaf spot and $15 \%$ for rust. Studies designed to obtain estimates of yield loss due to sorghum disease will need to recognize these patterns. For example, rather than assume a mean disease severity for the entire region, it will be more appropriate to establish critical severity levels at which diseases affect yield and to use the distributions provided here to compute the proportion of fields affected. Because several distribution functions provided good fit for disparate data from different diseases, we do not endorse the use of any particular one over the others. Instead, the choice for a particular model should be based on its goodness-of-fit to the data obtained, as well as its compatibility with the objectives of the study.

The reasons for the generally low disease severity observed during the 2 years of the survey are not clear. There was also little evidence to suggest that farmers employed disease management practices consciously, especially since their knowledge of foliar diseases was little. Conditions suitable for disease development existed as exemplified by the severe infections observed in some fields. Low disease severity was therefore thought to result in part from resistance in the cultivated local landraces, although some farmer practices, such as inter-cropping or early planting, may also have contributed to low disease levels. Moderate levels of partial resistance to multiple diseases have been reported in many traditional landraces (ICRISAT, unpublished information), while sorghum cultivar and species mixtures have been shown to reduce the severity of some sorghum diseases under experimental conditions (18). Doggett (3) also considered pathogens to have evolved alongside the traditional sorghum landraces establishing an equilibrium in which only low levels of infection occur. Such an explanation is consistent with data that fit negative bino-
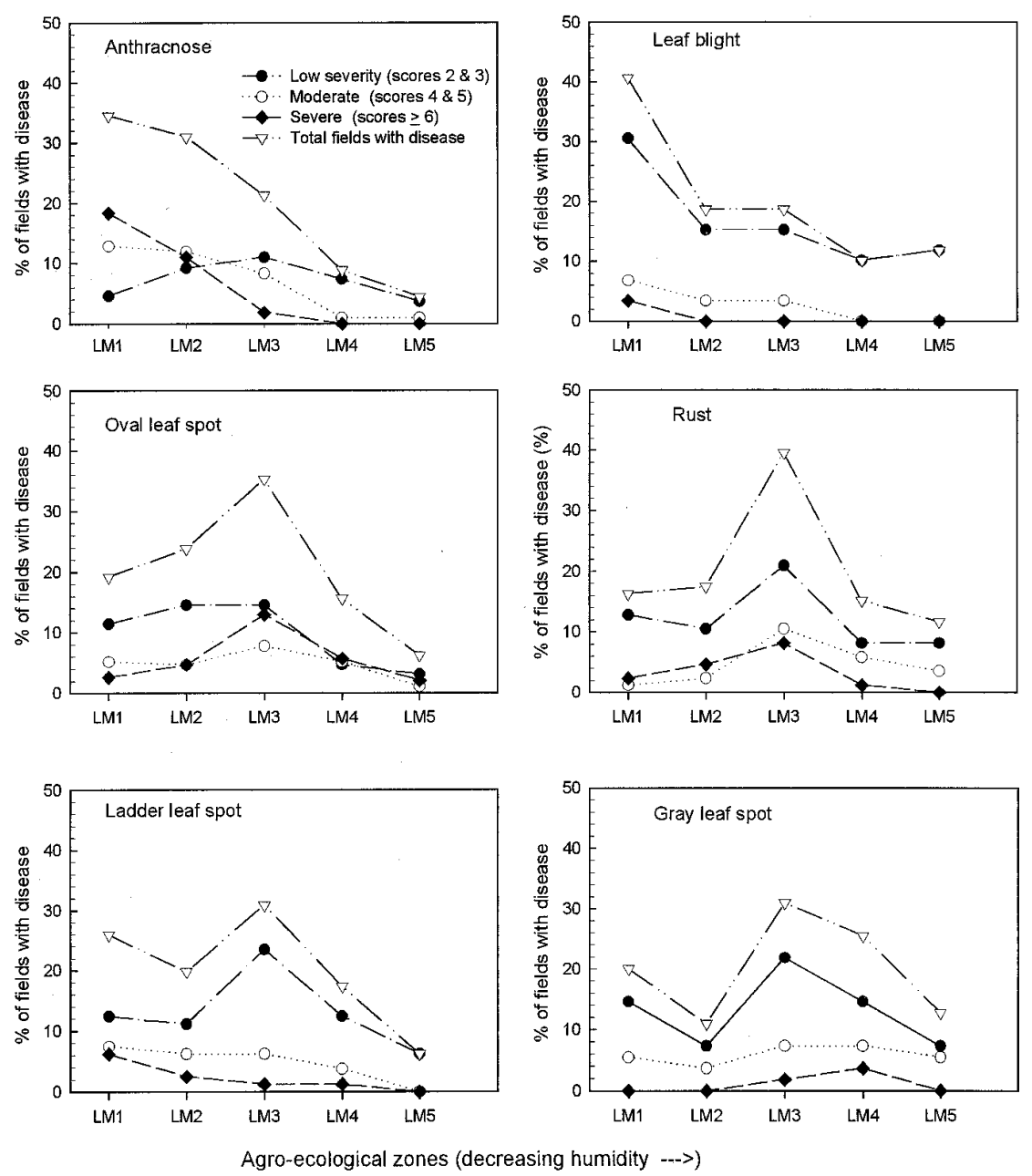

Fig. 3. Fields with low, moderately severe, and severe levels of disease, and total fields with disease in each of five agro-ecological zones surveyed in western Kenya, expressed as a percentage of the total number of fields in which the disease was observed for foliar diseases with a prevalence $>50 \%$ of all fields surveyed. LM1 $=$ warm-humid, mean annual rainfall $=1,600-1,800 \mathrm{~mm} ; \mathrm{LM} 2=$ warmhumid, 1,300-1,700 mm; LM3 = warm-humid, 900-1,500 mm; LM4 = warm-transitional, 800-900; LM5 = semi-arid 700-900 (see Table 1 for more detail).

mial or lognormal distributions such as those reported here.

Another possible explanation for the low diseases severity is that most of the diseases observed at low severity levels in this plants. It could be aroued, therefore, that the low severity observed is an artifact of sampling fields at advanced stages of crop maturity. This is unlikely, however, since epidemics in young plants would velopment and hence the disease severity levels observed during the survey. In any case, this argument should not dilute the importance of the findings of this study, diseases occurring prior to crop boot-stage that fail to increase in severity do not significantly reduce yields. Grain size in sorghum, and hence yield, is determined priafter anthesis $(4,19)$

The results of this study established the distribution patterns of anthracnose and 
leaf blight severity across agro-ecological zones. Severe disease, therefore, could be expected if susceptible cultivars were planted in the humid (LM1 and LM2) zones, while moderate disease could occur in LM3. Since rainfall and humidity appear to be the main factors distinguishing these zones $(2,10)$, it appears that severe anthracnose and leaf blight epidemics are favored by higher rainfall and humidity. Similarly, the development of severe ladder leaf spot (C. fusimaculans) appears to be favored by higher rainfall and humidity, gray leaf spot (C. sorghi) and oval leaf spot ( $R$. sorghicola) by lower rainfall, while rust ( $P$. purpurea) appears to be widespread irrespective of the rainfall and humidity regime. Intersection between curves for severe and moderate disease for anthracnose showed opposing effects to that for oval leaf spot. Severe anthracnose was observed in the more humid zones, while an increase in humidity coincided with a reduced prevalence of fields with severe levels of oval leaf spot. These differences indicate different ecological requirements for $C$. sublineolum and $R$. sorghi. Further research is needed on the epidemiology of oval leaf spot, gray leaf spot, rust, and ladder leaf spot to elucidate factors that influence the distribution of these diseases.

The influence of agro-ecological zones on distribution of disease severity has several implications on studies intended to obtain data on the importance of diseases to sorghum production in this region. Such studies would have to consider the fact that sorghum diseases occur as a complex, whose composition, incidence, and severity depends on the production environment, and adapt the methods accordingly. Studies relating disease severity to yield would therefore need to be replicated across several agro-ecological zones in order to be sensitive to the differences in complex constituents. Furthermore, such studies will need to include local landraces, such as those observed in the farmers' fields, in order to reflect losses encountered by farmers. In the meantime, sorghum varieties intended for release must be tested in locations representative of the different agro-ecological zones.

\section{LITERATURE CITED}

1. Bock, C. H., Jeger, M. J., Mughogho, L. K., Cardwell, K. F., Adenle, V., Mtisi, E., Akpa, A. D., Kaula, G., Mkasabina, D., and BlairMyers, C. 1998. Occurrence and distribution of Peronosclerospora sorghi (Western and Uppal [Shaw]) in selected countries of west and southern Africa. Crop Prot. 17:427-439.

2. Braun, H. M. H., and Other Staff of the Soil Survey of Kenya. 1980. Exploratory soil map and agro-climatic zone map of Kenya. Republic of Kenya Ministry of Agriculture, Kenya Soil Survey, Nairobi, Kenya.

3. Doggett, H. 1980. Sorghum diseases in east Africa. Pages 33-35 in: Sorghum Diseases, A World Review. R. J. Williams, R. A. Frederiksen, L. K. Mughogho, and G. D. Bengston, eds. ICRISAT, Patancheru, India.

4. Doggett, H. 1988. Sorghum, 2nd ed. Longman, London, UK.

5. Esele, J. P. E. 1995. Foliar and head diseases of sorghum. Afr. Crop Sci. J. 3:185-189.

6. FAO. 1999. FAO Quarterly Bulletin of Statistics, 12. FAO. Rome, Italy.

7. Guiragossian, V. 1986. Sorghum production constraints and research needs in eastern Africa. Pages 28-46 in: Proc. Regional Workshop Sorghum Millet Improvement in Eastern Africa, 5th. EARSAM, Nairobi, Kenya

8. Hulluka, M., and Esele, J. P. E. 1992. Sorghum diseases in eastern Africa. Pages 21-24 in: Sorghum and Millets Diseases: A Second World Review. W. J. A. de Milliano, R. A. Frederiksen, and G. D. Bergston, eds. ICRISAT, Patancheru, India.

9. Hulluka, M., and Gebrekidan, B. 1980. Diseases of sorghum in Ethiopia. Pages 36-39 in: Sorghum Diseases, A World Review. R. J. Williams, R. A. Frederiksen, L. K. Mughogho, and G. D. Bengston, eds. ICRISAT, Patancheru, India.

10. Jaetzold, R., and Schmidt, H. 1982. Farm Management Handbook of Kenya, Ministry of Agriculture, Kenya and German Agricultural Team (GAT) of the German Technical Cooperation (GTZ), Rossdolf, Germany, pp. 397.

11. Jeger, M. J. 1990. Mathematical analysis and modeling of spatial aspects of plant disease epidemics. Pages 53-88 in: Epidemics of Plant Diseases: Mathematical Analysis and Modeling. J. Kranz, ed. Springer-Verlag, New York.

12. King, S. B., and Mukuru, S. Z. 1994. An overview of sorghum, finger millet and pearl millet in eastern Africa with special attention to diseases. Pages 24-34 in: Breeding for Disease Resistance with Emphasis on Duarability. D. L. Danial, ed. Wageningen Agricultural University, Wageningen, The Netherlands.

13. Madden, L. V. 1983. Measuring and modeling crop losses at the field level. Phytopathology 73:1591-1596.

14. Marois, J. J., and Adams, P. B. 1985. Frequency distribution analyses of lettuce drop caused by Sclerotinia minor. Phytopathology 75:957-961.

15. McCullagh, P., and Nelder, J. A. 1983. Generalized Linear Models. Chapman and Hall, London, UK.

16. M'Ragwa, L. R., and Kanyenji, B. M. 1987. Strategies for improvement of sorghum and millet in Kenya. Pages 173-190 in: Food Grain Production in Semi-Arid Africa. J. M. Meyonga, T. Bezuneh, and A. Youdeowei, eds. OAU/STRC-SAFGRAD, Ouagadougou, Burkina Faso.

17. Mukuru, S. Z. 1993. Sorghum and millets in eastern Africa. Pages 55-62 in: Sorghum and Millets Commodities and Research Environment. Byth, D. E., ed. ICRISAT, Patancheru, India.

18. Ngugi, H. K. 1998. Epidemiology and management of sorghum anthracnose and leaf blight in Kenya. Ph.D. thesis. University of Reading, Reading, UK.

19. Peacock, J. M., and Wilson, G. L. 1984. Sorghum. Pages 249-279 in: The Physiology of Tropical Field Crops. P. R. Goldsworthy, and N. M. Fisher, eds. John Wiley, London, UK

20. Rutto, J. K. 1982. The status of sorghum improvement in Kenya. In: Proc. Regional Workshop on Sorghum Improvement in Eastern Africa, 17-21 Oct. 1982. B. Gebrekdan, ed. EARSAM, Nairobi, Kenya.

21. Teng, P. S. 1983. Estimating and interpreting disease intensity and loss in commercial fields. Phytopathology 73:1587-1590.

22. Teng, P. S., and Shane, W. W. 1983. Crop losses due to plant pathogens. CRC. Crit. Rev. Plant Sci. 2:21-47.

23. Thomas, M. D. 1992. Sorghum diseases in western Africa. Pages 25-29 in: Sorghum and Millets Diseases: A Second World Review. W. J. A. de Milliano, R. A. Frederiksen, and G. D. Bergston, eds. ICRISAT, Patancheru, India.

24. Wallace, G. B., and Wallace, M. M. 1953. Pamphlet No. 53. Tanganyika Department of Agriculture, Tanganyika.

25. Zadoks, J. C., and Schein, R. D. 1979. Epidemiology and Plant Disease Management. Oxford University Press, Oxford, UK. 